\title{
HUB UNGAN ANTARA VULVA HYGIENE DENGAN LAMA PENYEMBUHAN LUKA PERINEUM DI BPS NY S DESA GROBOG WETAN KECAMATAN PANGKAH KABUPATEN TEGAL TAHUN 2015
}

\author{
Se ventina Nurul Hidayah ${ }^{1}$ \\ Email: seventinanurulhidayah@yahoo.com \\ ${ }^{1}$ Program Studi D III Kebidanan Politeknik Harapan Bersama \\ Jl.Mataram no.09 Pesurungan Lor Kota Tegal
}

\begin{abstract}
Abstrak
Ibu nifas yang mengalami luka perineum sangat rentan terhadap terjadinya infeksi, karena luka perineum yang tidak dijaga dan kebersihannya tidak terjaga akan sangat berpengaruh terhadap lama kesembuhan luka perineum. Tujuan penelitian ini untuk mengetahui hubungan vuva hygiene dengan lama penyembuhan luka perineum. Penelitian ini merupkan jenis penelitian analitik. Desain atau rancangan penelitian yang digunakan dalam penelitian ini adalah case control atau kasus kontrol. Teknik pengambilan sampel dalam penelitian ini dengan nonprobability sampling yaitu sampel jenuh atau total sampling sebanyak 50 responden. Data primer didapatkan dari anamnesa dan observasi secara langsung terhadap responden.

Hasil penelitian dengan menggunakan Chi Square dengan menggunakan program SPSS dengan $\mathrm{dk}=$ 2 dan taraf kesalahan $5 \%$ (taraf kepercayaan 95\%) diperoleh $\mathrm{x}^{2}$ tabel $=3,481$ dan $\mathrm{x}^{2}$ hitung $=18,473$. Yang berarti $x^{2}$ hitung lebih besar dari $x^{2}$ tabel $(25,027>5,991)$ dan korelasi antara vuva hygiene pada ibu post partum dengan tingkat penyembuhan luka perineum didapatkan $\mathrm{P}$ value $=0,000$ yang berarti bahwa $\mathrm{P}$ value $<$ dari $\alpha$ ( $\mathrm{P}$ value $0,000<0,05$ ). Ini menunjukan bahwa ada Hubungan antara vuva hygiene pada ibu post partum dengan tingkat penyembuhan luka perineum Di BPS Ny S Desa Grobog Wetan Kecamatan Pangkah Kabupaten Tegal Tahun 2015 dengan responden yang melakukan vuva hygiene dengan teratur sebagian besar mengalami tingkat penyembuhan luka perineum dengan kategori cepat
\end{abstract}

Kata kunci : Vulva Hygiene, Penyembuhan Luka Perineum

\section{Pendahuluan}

Persalinan seringkali mengakibatkan perlukaan jalan lahir, luka-luka biasanya ringan tetapi kadang terjadi juga luka yang luas dan berbahaya, sehingga setelah persalinan harus selalu dilakukan pemeriksaan vuva dan perineum ${ }^{4}$. Luka bekas jahitan jalan lahir ini bila tidak dirawat dapat menjadi pintu masuk kuman dan menimbulkan infeksi, ibu menjadi panas, luka basah dan jahitan terbuka, bahkan ada yang mengeluarkan bau busuk dari jalan lahir (vagina) (Tari 2010). Ibu yang bersalin secara normal beberapa ada yang tidak mengalami robekan karena jalan lahirnya cukup elastis ketika dilalui bayi pada saat proses persalinan, namun ada yang memerlukan bantuan dokter maupun bidan untuk memperlebar jalan lahir dengan dilakukan episiotomi ${ }^{7}$. Ibu nifas yang mengalami luka perineum sangat rentan terhadap terjadinya infeksi, karena luka perineum yang tidak dijaga dengan baik dan kebersihan daerah perineum yang tidak terjaga kebersihannya akan sangat berpengaruh terhadap lama kesembuhan luka perineum ${ }^{1}$.

Angka Kematian Ibu (AKI) menurut Laporan Survei Demografi Indonesia (SDKI) terakhir memperkirakan Angka Kematian Ibu yaitu 420/100.000 kelahiran hidup (Trisnantoro L, 2011).

Masa nifas atau puerperium dimulai sejak 1 jam setelah lahirnya plasenta sampai dengan 6 minggu (42 hari) setelah itu. Asuhan selama periode nifas perlu mendapat perhatian karena sekitar 60\% Angka Kematian Ibu terjadi pada periode ini. Kematian ibu dapat terjadi pada masa nifas karena perdarahan atau sepsis. Penyebab perdarahan post partum yang kedua setelah retensio plasenta adalah robekan jalan lahir ${ }^{1}$. 
Luka pada perineum akibat episiotomy, ruptura, atau laserasi merupakan daerah yang tidak mudah untuk dijaga agar tetap bersih dan kering. Luka pada perineum dapat mengakibatkan infeksi akibat masuknya mikroorganisme ke dalam luka perineum ${ }^{2}$.

Infeksi dapat terjadi, tetapi sangat kecil kemungkinannya jika luka perineum dirawat dengan baik.

Di puskesmas Lebaksiu terdapat beberapa BPS diantaranya yaitu BPS Ny.S, BPS Ny.L, BPS Ny I, BPS Ny. A dan BPS Ny.L. Dari data hasil rekapitulasi yang diambil dari 3 bulan yang lalu yaitu dari tanggal 1 Desember 2014 sampai dengan tanggal 18 Februari 2015 diperoleh data ibu nifas di BPS Ny S sebanyak 44 jiwa, di BPS Ny L sebanyak 5 jiwa, di BPS Ny I sebanyak 3 jiwa, di BPS Ny A sebanyak 16 jiwa, dan di BPS Ny L sebanyak 33 jiwa. Dari data tersebut, jumlah ibu nifas yang mengalami rupture perineum paling banyak yaitu di BPS Ny S yaitu sebanyak 32 orang, sehingga peneliti mengambil tempat penelitian di BPS Ny S Desa Grobog Wetan.

Berdasarkan studi pendahuluan yang dilakukan peneliti pada 5 responden diperoleh data bahwa 3 responden mengalami penyembuhan luka selama 6-7 hari dan 2 responden mengalami penyembuhan luka 3-4 hari. Dari responden yang penyembuhan luka perineumnya lama menunjukkan bahwa keadaan luka yang masih basah.

\section{Metode Penelitian}

A. Tempat dan Waktu Penelitian Penelitian dilakukan di BPS Ny S Desa Grobog Wetan Kecamatan Pangkah Kabupaten Tegal pada bulan Mei sampai bulan Juni tahun 2015.

\section{B. Jenis Penelitian}

Penelitian ini merupakan jenis penelitian analitik. Rancangan penelitian yang digunakan dalam penelitian ini adalah case control atau kasus-kontrol yaitu suatu penelitian (survei) analitik yang mempelajari faktor resiko dengan menggunakan pendekatan retrospektif, artinya penelitian dimulai dengan mengidentifikasi kelompok yang terkena penyakit atau efek tertentu (kasus) dan kelompok tanpa efek (kontrol), kemudian mengidentifikasi faktor resiko terjadinya pada waktu yang lalu ${ }^{3}$.

C. Populasi dan Sampel

Populasi adalah seluruh ibu yang bersalin dan mengalami rupture perineum/robekan perineum dengan derajat robekan 1 dan 2 di BPS Ny. S berjumlah 50 orang. Sampel diambil dari catatan buku register persalinan di BPS Ny S Desa Grobog Wetan yaitu ibu post partum yang mengalami rupture perineum dengan derajat robekan 1 dan 2 pada bulan Mei 2015 sampai dengan bulan Juni tahun 2015 yaitu sebanyak 50 orang. Dari seluruh jumlah sampel, diambil 25 orang yang mengalami penyembuhan luka perineum dengan kategori lambat dan 25 orang yang mengalami penyembuhan luka perineum dengan kategori cepat.

D. Variabel Penelitian

Variabel dalam penelitian ini yaitu : Variabel independen vulva hygiene dan pola nutrisi variabel dependen tingkat penyembuhan luka perineum.

\section{E. Instrumen Penelitian}

Data primer diperoleh secara langsung dari responden melalui wawancara dan observasi terhadap variabel vulva hygiene dan tingkat penyembuhan luka perineum. Dan data sekunder diperoleh dari buku register ibu post partum di BPS Ny S Desa Grobog Wetan.

Adapun cara pengambilan data pada penelitian ini yaitu dengan cara: Mengidentifikasi ibu post partum yang mengalami rupture perineum dengan derajat robekan 1 dan 2 maksimal 10 hari post partum di BPS Ny S Desa Grobog Wetan pada bulan Mei sampai bulan Juni tahun 2015. Mendatangi ibu post partum pada hari ketiga dan hari ke tujuh setelah melahirkan untuk mengobservasi keadaan luka perineum dan untuk mendapatkan informasi mengenai vulva hygiene yang dilakukan ibu. 


\section{F. Analisis Data}

Analisa data dilakukan secara deskriptif dengan menggunakan bantuan komputer yang meliputi :

1) Analisa Univariat

Dari data primer dan data sekunder yang telah diperoleh, diolah kemudian dilakukan analisa secara deskriptif untuk membuat gambaran tentang suatu keadaan secara obyektif yaitu gambaran tentang vulva higyene dan tingkat penyembuhan luka perineum yang dibuat dalam bentuk tabel prosentase dan diberi penjelasanpenjelasan.

2) Analisa Bivariat

Teknik statistik yang digunakan untuk pengujian yaitu dengan Chi Square yaitu salah satu jenis uji komparatif non parametris yang digunakan untuk menguji dua kelompok data baik variabel independen maupun dependen yang berbentuk kategorik atau dapat juga dikatakan sebagai uji proporsi untuk dua peristiwa atau lebih.

Dalam melakukan uji statistic Chi Square menggunakan bantuan komputerisasi program Statistical Product and Service Solution (SPSS). Teknik ini mempunyai kaitan yang erat dengan rumus sebagai berikut :

$$
\text { Dimana : }
$$

$$
\mathrm{X}^{2}=\frac{\Sigma\left(F_{O}-F h\right)^{5}}{f h}
$$

$x^{2}=$ Chi kuadrat

$f_{0}=$ F yang diobservasi

$f_{h}=\mathrm{F}$ yang diharapkan

( Sugiyono, 2010 )

Dasar pengambilan keputusan

berdasarkan kriteria penelitian sebagai berikut :

1) Berdasarkan perbandingan Chi Square hitung dan table.

a. Ho ditolak jika Chi Square hitung > Chi Square table berarti ada hubungan antara vulva hygiene pada ibu post partum dengan tingkat penyembuhan luka perineum.

b. Ho diterima jika Chi Square hitung $<$ Chi Square table berarti tidak ada hubungan antara vulva hygiene pada ibu post partum dengan tingkat penyembuhan luka perineum.

2) Berdasarkan probabilitas

a. Ho ditolak jika $\mathrm{P}$ value $<0,05$ untuk signifikan $5 \%$ dengan derajat kepercayaan Confident Interval (CI) $=95 \%$, berarti ada hubungan antara vulva hygiene pada ibu post partum dengan tingkat penyembuhan luka perineum.

b. Ho diterima jika $\mathrm{P}$ value $>0,05$ untuk signifikan 5\% dengan derajat kepercayaan Confident Interval (CI) $=95 \%$, berarti tidak ada hubungan antara vulva hygiene pada ibu post partum dengan tingkat penyembuhan luka perineum.

Table 1 Pedoman untuk memberikan interpretasi terhadap koefisien korelasi

\begin{tabular}{cc}
\hline Interval Koefisien & Tingkat Hubungan \\
\hline $0,00-0,199$ & Sangat rendah \\
$0,20-0,399$ & Rendah \\
$0,40-0,599$ & Sedang / cukup \\
$0,60-0,799$ & Kuat \\
$0,80-1,000$ & Sangat kuat / sempurna \\
\hline
\end{tabular}

( Sugiyono, 2010)

Analisis hasil penelitian pada desain kasus kontrol yaitu menentukan Odds Rasio. Cara analisis ditentukan oleh apa yang akan diteliti, bagaimana peneliti mengambil kontrol (apakah matching atau tidak) dan terdapatnya variabel yang mengganggu atau tidak.

Pada penelitian ini, Odds rasio digunakan untuk mengetahui hubungan antara variable dependen (tingkat penyembuhan luka perineum) dan variable independen (vulva hygiene). Cara menghitung Odds rasio yaitu dengan case control / kasus kontrol tanpa matching yang dimulai dengan mengambil kelompok kasus $(\mathrm{A}+\mathrm{C})$ dan kelompok kontrol $(\mathrm{B}+\mathrm{D})$. Pada penelitian kasus kontrol yang dapat dinilai adalah berapa seringnya terdapat pajanan pada kasus dibandingkan pada kontrol. Odds rasio dapat dihitung dengan menggunakan tabel $2 \times 2$ : 
Table 2 Odds rasio

\begin{tabular}{lccc}
\hline \multirow{2}{*}{$\begin{array}{l}\text { Faktor } \\
\text { resiko }\end{array}$} & \multicolumn{2}{c}{ Faktor } & Efek \\
\cline { 2 - 3 } & Positif & Negatif & \\
\hline Positif & $\mathrm{A}$ & $\mathrm{B}$ & $\mathrm{A}+\mathrm{B}$ \\
Negatif & $\mathrm{C}$ & $\mathrm{D}$ & $\mathrm{C}+\mathrm{D}$ \\
\hline Jumlah & $\mathrm{A}+\mathrm{C}$ & $\mathrm{B}+\mathrm{D}$ & $\begin{array}{c}\mathrm{A}+\mathrm{B}+\mathrm{C}+ \\
\mathrm{D}\end{array}$ \\
\hline
\end{tabular}

\section{Hasil Dan Pembahas an}

A. Hasil

1) Analisa Univariat

Vulva hygiene berdasarkan hasil penelitian menunjukkan bahwa karateristik ibu post partum di BPS Ny S Desa Grobog Wetan tahun 2015 berdasarkan latihan kegel seperti :

Table 3 Frekuensi Latihan Kegel pada Ibu post partum

\begin{tabular}{llcc}
\hline No & Latihan Kegel & F (n) & $(\boldsymbol{\%})$ \\
\hline 1. & Tidak melakukan & 21 & 42 \\
2. & Melakukan & 29 & 58 \\
\hline & Jumlah & 50 & 100 \\
\hline ( Sumber data : Data primer ) & &
\end{tabular}

Berdasarkan tabel.3 dapat diketahui karateristik responden berdasarkan frekuensi latihan kegel sebagian besar terdapat responden yang melakukan vulva hygiene yaitu sebanyak 29 responden $(58 \%)$.

a. Tingkat penyembuhan luka perineum

Dari 50 responden berdasarkan tingkat penyembuhan luka perineum yang termasuk dalam kategori lambat yaitu sebanyak 25 responden $(50 \%)$ dan yang termasuk dalam kategori cepat yaitu 25 responden (50\%).

b. Pola Nutrisi

Table 4 Pola Nutrisi berdasarkan komposisi makanan

\begin{tabular}{llcc}
\hline No & Komposisi nutrisi & (n) & $\mathbf{( \% )}$ \\
\hline 1. & Tidak seimbang & 4 & 8 \\
2. & Seimbang & 46 & 92 \\
\hline & Jumlah & 50 & 100 \\
\hline
\end{tabular}

(Sumber data: Data primer )

Berdasarkan tabel 4. dapat diketahui bahwa karateristik responden berdasarkan pola nutrisi yang dikonsumsi sehari - hari dilihat dari segi komposisi makanan sebagian besar termasuk dalam kategori seimbang yaitu sebanyak 46 responden (92\%).

Table 5 Pola Nutrisi berdasarkan Keteraturan makan

\begin{tabular}{llcc}
\hline No & Keteraturan makan & (n) & $\mathbf{( \% )}$ \\
\hline 1. & Kurang teratur & 26 & 52 \\
2. & Teratur & 24 & 48 \\
\hline \multicolumn{2}{l}{ Jumlah } & 50 & 100 \\
\hline ( Sumber data : Data primer ) & &
\end{tabular}

Berdasarkan tabel 5 dapat diketahui bahwa karateristik responden berdasarkan pola nutrisi yang dikonsumsi sehari - hari dilihat dari segi keteraturan makan sebagian besar termasuk dalam kategori kurang teratur yaitu sebanyak 26 responden (52\%).

Table 6 Pola Nutrisi berdasarkan Porsi makanan

\begin{tabular}{|c|c|c|c|}
\hline No & Porsi makan & (n) & $(\%)$ \\
\hline 1. & Kurang & 26 & 52 \\
\hline 2. & Cukup & 24 & 48 \\
\hline & Jumlah & 50 & 100 \\
\hline
\end{tabular}

2) Analisa Bivariat

Hubungan antara Vulva hygiene pada ibu post partum dengan tingkat penyembuhan luka perineum.

Berdasarkan tabel 5.7 dapat diketahui bahwa responden yang tidak melakukan Vulva hygiene lebih banyak yang mengalami penyembuhan luka perineum dengan kategori lambat yaitu 18 responden (85,7\%). Sedangkan responden yang melakukan vulva hygiene sebagian besar mengalami penyembuhan luka perineum dengan kategori cepat yaitu 22 responden $(75,9 \%)$.

B. Pembahasan

1) Karateristik responden

a) Vulva hygiene

Dari tabel 3 hasil penelitian terhadap 50 responden didapatkan karateristik berdasarkan ibu post partum yang melakukan Vulva hygiene yang terbanyak adalah yang melakukan latihan kegel yaitu sebanyak 29 responden $58 \%$.

b) Tingkat penyembuhan luka perineum 
Dari tabel 4 hasil penelitian terhadap 50 responden didapatkan karateristik berdasarkan tingkat penyembuhan luka perineum terdapat 25 responden $50 \%$ yang mengalami tingkat penyembuhan luka perineum dengan kategori lambat dan 25 responden $50 \%$ yang mengalami tingkat penyembuhan luka perineum dengan kategori cepat.

Penyembuhan luka adalah suatu proses upaya perbaikan jaringan pada luka. Menurut Dewi (2012) ada 2 tingkatan proses penyembuhan luka perineum, yaitu lambat apabila pada hari ke-3 luka belum kering dan menutup, tetapi pada hari ke-7 luka mulai menutup dan cepat apabila pada hari ke-3 luka mulai kering dan menutup serta pada hari ke-7 luka sudah menutup dengan baik. Sedangkan menurut Mochtar (2011), luka - luka pada jalan lahir jika tidak disertai infeksi akan sembuh dalam 6 - 7 hari.

c) Pola nutrisi yang dilihat dari segi komposisi

Dari tabel 4.3 hasil penelitian terhadap 50 responden didapatkan karateristik berdasarkan pola nutrisi yang dilihat dari segi komposisi yang terbanyak adalah seimbang yaitu sebanyak 46 responden $92 \%$.

d) Pola nutrisi yang dilihat dari segi keteraturan makan

Dari tabel 4.4 hasil penelitian terhadap 50 responden didapatkan karateristik berdasarkan pola nutrisi yang dilihat dari segi keteraturan makan yang terbanyak adalah kurang teratur yaitu sebanyak 26 responden $52 \%$.

e) Pola nutrisi yang dilihat dari segi porsi cukup

Dari tabel 4.5 hasil penelitian terhadap 50 responden didapatkan karateristik berdasarkan pola nutrisi yang dilihat dari segi porsi cukup yang terbanyak adalah kurang yaitu sebanyak 26 responden $52 \%$.

2) Mengetahui tingkat penyembuhan luka perineum menurut pola nutrisi

a) Pola nutrisi yang dilihat dari segi komposisi
Berdasarkan tabel 5.0 dapat diketahui bahwa responden dengan komposisi nutrisi yang tidak seimbang lebih banyak mengalami penyembuhan luka perineum dengan kategori lambat yaitu 4 responden (100\%). Sedangkan responden dengan komposisi nutrisi yang seimbang sebagian besar mengalami penyembuhan luka perineum dengan kategori cepat yaitu 25 responden $(54,3 \%)$.

b) Pola nutrisi yang dilihat dari segi keteraturan makan

Berdasarkan tabel 5.1 dapat diketahui bahwa responden dengan pola makan yang kurang teratur lebih banyak yang mengalami penyembuhan luka perineum dengan kategori lambat yaitu 14 responden (53,8\%). Sedangkan responden dengan pola makan teratur sebagian besar mengalami penyembuhan luka perineum dengan kategori cepat yaitu 13 responden $(54,2 \%)$.

c) Pola nutrisi yang dilihat dari segi porsi cukup

Berdasarkan tabel 5.2 dapat diketahui bahwa responden dengan porsi makan yang kurang lebih banyak yang mengalami penyembuhan luka perineum dengan kategori lambat yaitu 14 responden $\quad(53,8 \%)$. Sedangkan responden dengan porsi makan cukup sebagian besar mengalami penyembuhan luka perineum dengan kategori cepat yaitu 13 responden $(54,2 \%)$.

\section{Kesimpulan}

A. Karateristik berdasarkan vulva hygiene sebagian besar terdapat responden yang melakukan latihan kegel yaitu sebanyak 29 responden $(58 \%)$.

B. Karateristik berdasarkan tingkat penyembuhan luka perineum dari 50 responden yang termasuk dalam kategori lambat yaitu sebanyak 25 responden $(50 \%)$ dan yang termasuk dalam kategori cepat yaitu 25 responden $(50 \%)$.

C. Karateristik responden berdasarkan pola nutrisi yang dikonsumsi sehari - hari dilihat dari segi :

1) Komposisi sebagian besar 
termasuk dalam kategori seimbang yaitu sebanyak 46 responden $(92 \%)$.

2) Keteraturan makan sebagian besar termasuk dalam kategori kurang teratur yaitu sebanyak 26 responden $(52 \%)$.

D. Porsi cukup sebagian besar termasuk dalam kategori kurang yaitu sebanyak 26 responden (52\%).

E. Tingkat penyembuhan luka perineum menurut pola nutrisi dapat dilihat dari segi :

1) Komposisi nutrisi, dapat disimpulkan menurut prosentase terbesar responden yang mengalami tingkat penyembuhan luka perineum dengan kategori lambat paling tinggi pada responden dengan komposisi nutrisi yang tidak seimbang yaitu sebanyak 4 responden $100 \%$.

2) Keteraturan makan, dapat disimpulkan menurut prosentase terbesar responden yang mengalami tingkat penyembuhan luka perineum dengan kategori cepat paling tinggi pada responden dengan pola makan teratur yaitu sebanyak 13 responden 54,2\%.

3) Porsi cukup, dapat disimpulkan, menurut prosentase terbesar responden yang mengalami tingkat penyembuhan luka perineum dengan kategori cepat paling tinggi pada responden dengan porsi makan cukup yaitu sebanyak 13 responden 54,2\%.

F. Berdasarkan vulva hygiene, tingkat penyembuhan luka perineum dengan kategori cepat sebagian besar tedapat pada responden yang melakukan latihan kegel yaitu sebanyak 22 responden $(75,9, \%)$.

G. Ada hubungan antara vulva hygiene pada ibu post partum dengan tingkat penyembuhan luka perineum. Berdasarkan analisis bivariat dengan Chi Square dengan menggunakan program SPSS dengan $\mathrm{dk}=1$ dan taraf kesalahan 5
$\%$ (taraf kepercayaan 95\%) diperoleh $\mathrm{x}^{2}$ tabel $=3,481$ dan $\mathrm{x}^{2}$ hitung $=18,473$. Yang berarti $x^{2}$ hitung lebih besar dari $x^{2}$ tabel $(18,473>3,481)$ dan korelasi antara Vulva hygiene pada ibu post partum dengan tingkat penyembuhan luka perineum didapatkan $\mathrm{P}$ value = 0,000 yang berarti bahwa $\mathrm{P}$ value < dari $\alpha$ ( $\mathrm{P}$ value $0,000<0,05)$. Hal ini menunjukkan bahwa Ho ditolak dan Ha diterima yang berarti ada hubungan antara Vulva hygiene pada ibu post partum dengan tingkat penyembuhan luka perineum. Dari hasil perhitungan $\mathrm{x}^{2}$ didapatkan nilai spearman's rank sebesar 0,608. Yang menunjukkan besarnya hubungan antara Vulva hygiene pada ibu post partum dengan tingkat penyembuhan luka perineum. Dengan tingkat hubungan kuat.

H. Berdasarkan Odds rasio dapat disimpulkan bahwa ibu yang melakukan Vulva hygiene mempunyai resiko 18,9 kali mengalami tingkat penyembuhan luka perineum dengan kategori cepat dibandingkan dengan ibu yang tidak melakukan Vulva hygiene.

I. Berdasarkan analisa bivariat yang telah dilakukan antara variabel independent (Vulva hygiene, pola nutrisi) dengan variabel dependent (tingkat penyembuhan luka perineum) menggunakan uji statistik Chi Square, hasilnya adalah :

1) Yang mempunyai hubungan antara kedua variabel tersebut yaitu vulva hygiene yang dilakukan dengan membersihkan daerah luka setelah bak dan bab dengan sabun dan air mengalir, basuh dari arah depan kearah belakang, vulva hygiene yang dilakukan dengan mengganti pembalut setiap 4 - 6 jam dan latihan kegel.

2) Yang tidak mempunyai hubungan antara kedua variabel tersebut yaitu pola nutrisi yang dilihat dari segi keteraturan 
makan dan porsi cukup

\section{Daftar Pus taka}

[1] Ambarwati E, 2009. Asuhan Kebidanan Nifas. Mitra Cendekia : Yogyakarta

[2] Huliana M. 2003. Perawatan Ibu Pasca Melahirkan. Puspa Swara : Jakarta

[3] Prawirohardjo Sarwono. 2006. Buku Acuan Nasional pelayanan Kesehatan Maternal dan Kesehatan. YBP-SP: Jakarta

[4] Sumarah, dkk. 2010. Perawatan Ibu bersalin (Asuhan Kebidanan Ibu Bersalin). Jakarta : Fitramaya

[5] Slameto. 2003. Belajar dan FaktorFaktor yang Mempengaruhinya. Jakarta: Rineka Cipta.

[6] Varney H, 2009. Buku Ajar Asuhan Kebidanan Vol.1.EGC: Jakarta

[7] Zury, 2011. Perawatan Perineum pada masa nifas. http://infoseputar ilmu keidanan.Zury.blogspot.com/2011/0 5/perawatan masa nifas diakses tanggal 26 februari 2015 